\title{
EVALUATION OF INFECTION IN FIRST THREE MONTHS OF RENAL TRANSPLANT - A HOSPITAL BASED STUDY
}

\author{
ISLAM MN ${ }^{1}$, AKTER M$^{2}$, BHUIYAN FK ${ }^{3}$, AHMED PI ${ }^{4}$, RAHMAN MM ${ }^{5}$, AREFIN SZ ${ }^{6}$, RASHID HU7
}

\begin{abstract}
Background:The success of renal transplantation depends on a compromise between achieving sufficient immunosuppression to avoid rejection of the graft and maintaining a sufficient level of immuno competence to protect the recipient from infection. This study was undertaken to findout the prevalence of infection of renal allograft, to determine cause of infection, isolation of organism, antibiotic sensitivity and to evaluation of fate of infection within first three months of post transplant period.
\end{abstract}

Methods: All the subjects of this study had received live related renal transplantation. Triple immunosuppressive therapy was started day before transplantation. Before enrollment in this study, all base line investigations of recipient and donor were done. All the patients were investigated at $3^{\text {rd }}, 7^{\text {th }}, 14^{\text {th }}, 21^{\text {st }}, 28^{\text {th day }}$, end of $2^{\text {nd }}$ and $3^{\text {rd }}$ month and whenever infection was suspected any time within first 3 months of transplantation. Patients of primary graft failure were excluded from this study. Results were expressed as mean \pm standard deviation (mean \pm $S D)$. Fisher exact test or chi-square tests were performed for data analysis. All analysis were done using SPSS windows package and $p$ value $<0.05$ were considered significant.

Results:In the present study, 71\% patients had suffered from infection within first 3 months of post transplant period. Among them $71 \%$ occurred during hospital stay. Infection rate was $62 \%$ at the first month followed by $25 \%$ in $2^{\text {nd }}$ month and $13 \%$ at $3^{\text {rd }}$ month. Ninty six percent causes were bacterial infection and $4 \%$ were viral infection. Bacterial infection included urinary tract infection (79\%), respiratory tract infection (6\%), septicaemia (7\%) and wound infection (4\%). During follow up, most of the UTI were of bacterial origin, male and female had suffered from similar incidence of UTI (72\% vs 69\%), that was statistically insignificant ( $p=N S)$. Most of the episodes of UTI (90\%) were associated with bacteriuria caused by E.coli.

Conclusion: In the present study showed that, infection was the most common complication within first 3 months of transplant patient. UTI was the most common and remains major cause of morbidity of renal transplant recipients.

J Dhaka Med Coll. 2014; 23(2) : 153-156.

\section{Introduction}

Improvements in general clinical care arising from greater experience, improvements in methods of organ procurement, surgical technique, recipient selection and a greater awareness of the type and timing of infections, the incidence of lethal and non lethal infections decreased significantly. The success of renal transplantation depends on a compromise between achieving sufficient immunosuppression to avoid rejection of the graft and maintaining a sufficient level of immunocompetence to protect the recipient from infection. Despite this success, infection still

1. Dr. Md. Nazrul Islam, Associate Professor, Department of Nephrology, Dhaka Medical College, Dhaka

2. Dr. Mursheda Akter, Associate Professor, Department of Microbiology, Dhaka Central International Medical College, Dhaka.

3. Dr. Ferdous Kamal Bhuiyan, Assistant Professor, Department of Nephrology, Dhaka Medical College, Dhaka.

4. Dr. Parvez Iftekhar Ahmed, Assistant Professor, Department of Nephrology, Dhaka Medical College, Dhaka.

5. Dr. Md. Mostafizur Rahman, Assistant Professor, Department of Urology, Dhaka Medical College, Dhaka.

6. Dr. Md. Shakib uz Zaman Arefin, Assistant Professor, Department of Nephrology, Kidney Foundation Hospital, Dhaka.

7. Prof. Harun Ur Rashid, Chief Consultant, Kidney Foundation Hospital, Dhaka.

Correspondence: Dr. Md. Nazrul Islam, Associate Professor, Department of Nephrology, Dhaka Medical College,

Dhaka. Email: nazrul.rita@gmail.com 
occurs in more than two thirds of transplant recipients and remains the leading cause of death in this patient population ${ }^{1}$.In our country, data regarding infection of renal allograft recipient at earlier post transplant period are scarse. Therefore, the present study was carried out to find out the prevalence of infection, determine the cause of infection, isolation of causative organisms and their susceptibility pattern to common antimicrobial agents as well as type and consequence of infection of renal allograft recipient.

\section{Methods:}

Type, place and period of study: This prospective randomized clinical study was carried out in the Dept. of Nephrology, BSMMU, Dhaka, over a period of two years from January 2002 to December 2003.

Study Population: Total number of patients were $31(\mathrm{n}=31), 18$ males and 13 females with mean age $27 \pm 8.8$ yrs were included in this study. All patients received live related renal transplantation. They were studied prospectively for 3 months after transplantation.

Exclusion Criteria: Subjects who had primary graft failure after transplantation.

\section{Immunosuppression:}

Triple immunosuppressive therapy, started day before Transplantation. Acute Rejection was treated by 500mg Methyl prednisolone for successive 3 days.

Per operative antibiotic prophylaxis and postoperative care: All patients received $1 \mathrm{gm}$ intravenous ceftriaxone in peroperative period. Patients did not receive prophylactic agents for CMV and Pneumocystis cariniibut isoniazid was given for those patients who were suffering from tuberculosis previously and mantoux test revealed $>5 \mathrm{~mm}$ induration. After discharge from hospital, patients were regularly seen at the out patient department and when indicated, culture and other diagnostic measures were performed.

\section{Operational Definitions:}

Infectious episode was used to indicate every episode of presumed or proved infection. Five groups of infectious diseases were distinguished: urinary tract infections (UTIs), respiratory tract infections (RTIs), septicaemia, wound infecions and viral (CMV) infections.

UTI :Although the presence of bacteriuria with a concentration of at least $10^{5}$ organism per $\mathrm{ml}$. in the midstream clean catch or catheterized sample of urine fulfilled the criteria for UTI in renal transplant recipients, other criteria such as pyuria ( $>10$ pus cell/HPF) fever and dysuria were frequently used for diagnosing UTI. UTI was considered to be catheter related if infection occurred during urethral catheterization or within 24 hours after catheter removal with growth of organisms from catheter tip culture.

RTI were diagnosed according to respiratory sign symptoms with radiologic finding and positive sputum microscopic examination and culture.

Wound infection was defined as the presence of purulent discharge from a surgical wound with positive culture.

Septicaemiawas defined as growth of organism on blood culture.

CMV disease was based on the presence of clinical symptoms (fever, arthralgia, myalgia and organ involvement) and detection of antigen or viral DNA of CMV from blood.

\section{Results:}

The results are given below:

Complications at Earlier Post Transplant Period: Among all the studied patients, during observation period, infectious complications occurred in $22(71 \%)$. Acute rejection and surgical complication were observed in $26 \%$ and 19\% respectively (Table-I).

Table I

Early Complications of Transplant

\begin{tabular}{lcc}
\hline Complication & $\begin{array}{c}\text { No. of } \\
\text { Patients }\end{array}$ & $\begin{array}{c}\text { \% of } \\
\text { Patients }\end{array}$ \\
\hline Infection & 22 & 71 \\
Acute Rejection & 08 & 26 \\
Surgical Complication & 06 & 19 \\
\hline
\end{tabular}


Types of infections (in First Three Months): A total of 22 patients had suffered from different types of infection. Among them 42 (79\%) episodes of UTI, $3(6 \%)$ episodes of RT1, 2 (4\% episodes of wound infection and 4 (7\% septicaemia. Bacteria were responsible for 5 (96\%) episodes and $2(4 \%)$ were due to vire infection (Fig. 1).

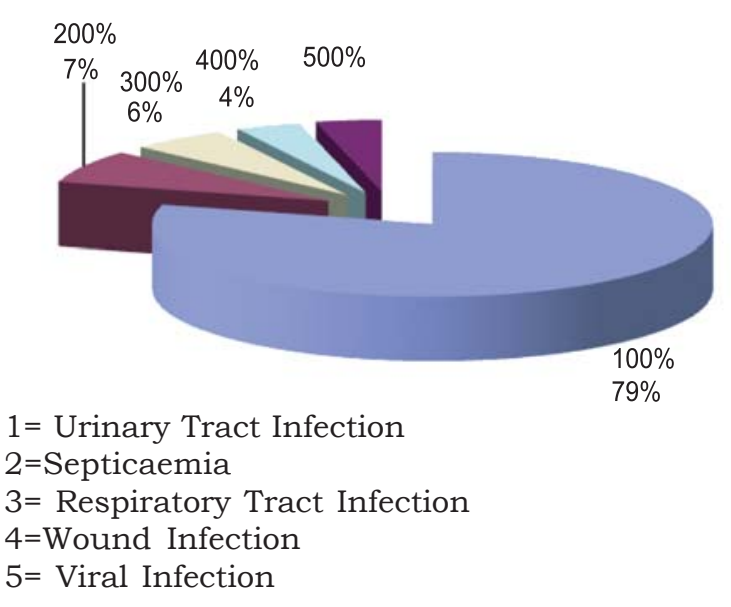

Fig.-1: Type of Post Transplant Infections

Organisms isolated: During the first 3 months of post transplantperiod,among the 31 transplant recipients, 11 suffered from single episode and another 11 suffered from two or more infectious episodes.Five types of pathogens were isolated by culture from different specimens at different times.Among them $E$. coli were 50 (77\%),Pseudomonas $6(9 \%)$, Klebsiella 5 (8\%), Staphylococcus 3 (4.5\%) and Entercoccus 1 (1.5\%) (Figure 2).

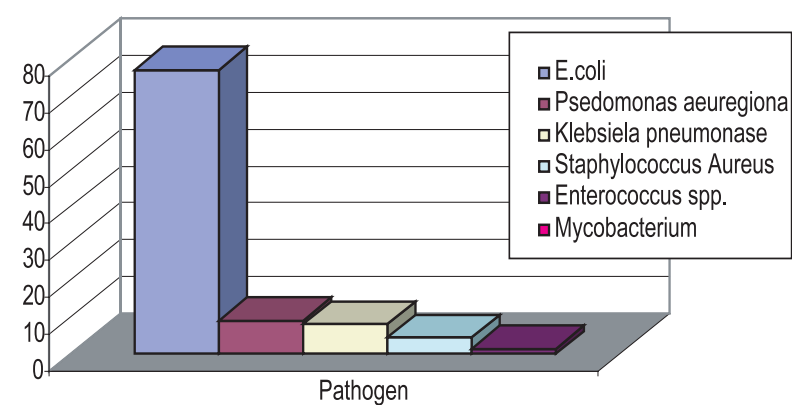

Fig.-2: Organisms Isolated

\section{Organism causing UTI:}

The bacterial cause of UTI was 38 (90\%). Among them E. coli 34 (88\%) Klebsiella2 (6\%), Pseudomonas - $1(3 \%)$ and Enterococcus - 1
(3\%). Only 2 episodes of UTI were associated with septicaemia (Figure 3).

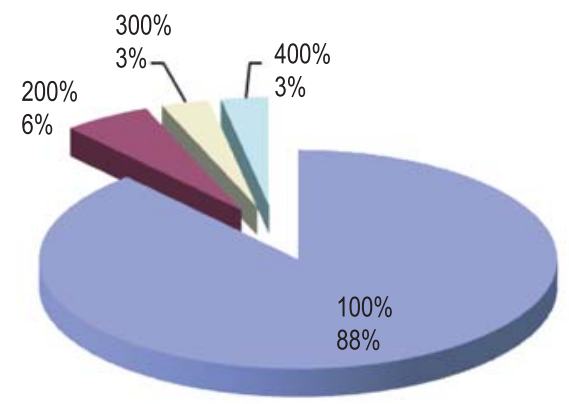

$1=$ E.coli

$2=$ Klebsiella

$3=$ Pseudomonas

4= Enterococcus

Fig.-3: Organism Causing UTI

\section{Discussion}

With increasing experience, renal transplantation now offers equivalent or better patient survival than haemodialysis. Recipients of renal allograft in developing countries may be more prone to certain complications contributing to the risk for infection ${ }^{2-4}$. In the present study, $71 \%$ patients had suffered from infection within first 3 months of post transplant period. Among them $71 \%$ occurred during hospital stay. Infection rate was $62 \%$ in the first month followed by $25 \%$ in $2^{\text {nd }}$ month and $13 \%$ at $3^{\text {rd }}$ month. Ninty six percent causes were bacterial infection and $4 \%$ were viral infection. Bacterial infection included urinary tract infection $(79 \%)$, respiratory tract infection $(6 \%)$, septicaemia $(7 \%)$ and wound infection (4\%). During follow up, most of the UTI were of bacterial origin, male and female had suffered from similar incidence of UTI (72\% vs 69\%), that was statistically insignificant. Most of the episodes of UTI $(90 \%)$ were associated with bacteriuria caused by E.coli. The occurrence of UTI was associated with the duration of urethral catheterization. Mean duration of urethral catheterization was $11.8 \pm 6.5$ days. Incidence of UTI increased significantly when the duration of urethral catheterization was more than 7 days. Similar incidence of UTI was found in ureteric stented and non stentedpatients $(73 \%$ vs $69 \%)$ which was statistically insignificant. The patients, who were not stented, had more urological complications and more incidence of UTI. In the present study, $E$. 
coli was the commonest isolated pathogen constituting $77 \%$ and sensitivity pattern revealed that, all isolates were sensitive to ceftriaxone, ciprofloxacin and ceftazidime, in between 67 to $100 \%$ except Pseudomonas, which was $33 \%$ sensitive to ceftriaxone and ciprofloxacin and $50 \%$ to ceftazidime. Pathogens showed higher resistance to ampicillin, cotrimoxazole and cephradine like above mentioned study. There were only $6 \%$ RTI, mostly caused by Klebsiell apneumoniae followed by mycobacterium tuberculosis. Four percent had wound infection and $7 \%$ septicaemia. There were two episodes of sepsis followed by UTI. There were two (4\%) episodes of viral infection, both were CMV infection and occurred at $3^{\text {rd }}$ month of post transplant period. No case of invasive fungal disease or pneumonia caused by Pneumocystis carinïweredetected. Marahaet al. ${ }^{5}$ reported that $60 \%$ of all infections were UTI, male and female had suffered from UTI $70 \%$ and $42 \%$ respectively. Fifty four percent had single episode and $46 \%$ had recurrent UTI. $83 \%$ UTI presented with bacteriuria. In the present study, there were two cases of pneumonia caused by Klebsiellapneumoniae at the end of first month of transplantation and no case of Pneumocystis carinii was detected by regular screening of sputum by Giemsa staining. Renal transplant patients developed tuberculosis as reported earlier are $12 \%$ in Indian subcontinent ${ }^{3}, 3.5 \%$ in Saudi Arabia ${ }^{6}, 3.64 \%$ in Argentina ${ }^{7}, 0.8 \%$ in Spain $^{8}$ and $1.7 \%$ in United Kingdom ${ }^{9}$. Rashid et al. ${ }^{10}$ showed that incidence of tuberculosis was about $6 \%$ in Bangladesh among transplant recipients. The interval between development of tuberculosis in post transplant period varies from 1 month to 10 years ${ }^{3,11}$. In the present study, a single case had suffered from milliary tuberculosis at $3^{\text {rd }}$ month of transplantation, diagnosed by microscopic examination of sputum. The incidence of wound infection was low(4\%) in the present study, as in other recent studies ${ }^{12,13}$. In the present study, two episodes or $4 \%$ of all infection had suffered from CMV infection. One of which was primary infection and the other was reactivation. One case was presented with concomitant acute rejection and sepsis. Incidence of sepsis was $4(7 \%)$, that occurred during hospital stay after transplantation. None of the patients had invasive fungal disease other than oropharyngeal candidiasis. Acute rejections occurred in $8(26 \%)$ cases

\section{Conclusion}

Form this study, considering all parameters, it can be concluded that, infection is the commonest complication in transplant patient within $1^{\text {st }}$ three months of transplantation. Most cases of mortality were associated with infection and CVD.

\section{References:}

1. Rubin RH. Infectious disease complications of renal transplantation. Kidney Int 1993; 44:221-36.

2. Cantarobich F, Vazquez M, Garcia WD, et al. Special infections in organ transplantation in South America. Transplant Proc 1992; 24: 1902-5.

3. Ianhez LE, Sampaio M, Fonseca JA, et al. The influence of Socioeconomic conditions in renal post transplant infection. Transplant Proc 1992; 24: 3100-2.

4. Naqvi A, Akther F, Naqvi R, et al. Problem of diagnosis and treatment of tuberculosis following renal transplantation. Transplant Proc 1997; 29: 3051.

5. Maraha B, Bonten $\mathrm{H}$, Van Hooff $\mathrm{H}$, et al. Infectious complications and antibiotic use in renal transplant recipients during a one year follow up. ClinMicrobiol Infect 2001; 7: 619-25.

6. Qunibi WY, Sibai MB, Taher S, et al. Mycobacterial infection after renal transplantation report of 14 cases and review of literature. Q J M 1990; 77: 1039-41.

7. Lattes R, Radisic M, Rial M, et al. Tuberculosis in renal transplant recipient. Transplant Infect Dis 1999; 1: 98-104.

8. Aguada JM, Herrero JA, Gavalda J, et al. Clinical presentation and outcome of tuberculosis in kidney, liver, and heart transplant recipients in Spain. Transplant 1997; 63: 1278-86.

9. Higgins RM, Cahn AP, Porter D, et al. Mycobacterial infection after renal transplantation Q J M 1991;78: 145-9

10. Rashid HU, Rasul G, Rahman MH. Experience of kidney transplantation in Bangladesh. Transplant Proc 1992; 24: 1831-7.

11. Lubani MM, Doudin KI, Sharda DC, et al. Congenital chloride diarrhoeain Kuwati children.Eur J Pediatr 1998; 148: 333-4.

12. Fox BC, Sollinger HW, Belzer FO, et al. A prospective randomized double-blind study of trimethoprimsulfamethoxazole for prophylaxis infection in renal transplantation: clinical efficacy, absorption of trimethoprim sulfamethoxazole, effects on the microflora, and the cost benefit of prophylaxis. Am J Med 1990; 89: 255-74.

13. Capocasale E, Mazzoni MP, Tondo S, et al. Antimicrobial prophylaxis with ceftriaxone in renaltransplantation. Chemetherapy 1994; 40: 435-40. 